\title{
Vitrectomy and fluid/silicone-oil exchange for giant retinal tears: results at six months
}

\author{
P. K. LEAVER, R. J. COOling, E. B. FERETIS, J. S. LEAN, ANd D. McLEOd \\ From the Surgical Vitreoretinal Unit, Moorfields Eye Hospital, London
}

SUMMARY The results of vitrectomy combined with fluid/silicone-oil exchange in 73 eyes with giant retinal tears are reported at six months after surgery. Initial anatomical success was achieved in 71 out of 73 eyes $(97 \%)$ and, prior to removal of silicone-oil, in 66 out of 73 eyes $(90 \%)$. In 63 eyes $(86 \%)$ the retina remained attached six months after surgery. Of these visual acuity was $6 / 60$ or better in $44(70 \%)$. The high proportion of eyes with macular detachment before surgery and the frequency of macular abnormalities are thought to account for reduced vision in many of the anatomically successful cases.

Giant retinal tears (GRTs) present a formidable challenge to the retinal surgeon. Not only are they difficult to close but long-term complications of initially successful surgery are frequent. Nevertheless, the advent of closed intraocular microsurgical techniques has aroused fresh interest in, and even enthusiasm for, the treatment of GRTs. ${ }^{1-7}$

Most recent reports have described the use of fluidair or fluid-gas exchange via either the pars plana or the limbus after vitreolensectomy in association with prone positioning of the patient at surgery. ${ }^{25}$ Variations on this method, including retinal suturing, have also been described. ${ }^{136-8}$ However, there have been very few reports of long-term results to indicate that the prognosis for useful vision has been improved significantly by these methods compared with previous treatment.

For many years Scott has championed the use of silicone oil in the management of GRTs. ${ }^{9-11}$ Leaver and Lean recently published a preliminary report of the results using vitrectomy and fluid/silicone-oil exchange at Moorfields Eye Hospital, ${ }^{3}$ and the improvement afforded by this method has been sustained. ${ }^{4}$ Živojnovic et al. ${ }^{8}$ use similar methods. An increasing groundswell of opinion now exists in European centres to suggest that the use of silicone oil as the means of intraocular tamponade may be more effective than gases in the management of GRTs.

It is the purpose of this paper to report the results at six months after vitrectomy and silicone-oil exchange in a large series of patients with GRTs.

Correspondence to P. K. Leaver, FRCS, Moorfields Eye Hospital, City Road, London ECIV 2PD.

\section{Patients and methods}

We define a giant retinal tear as a peripheral break extending through $90^{\circ}$ or more of the retinal circumference in which the vitreous gel is attached essentially to the anterior flap thereby allowing independent mobility of the posterior edge of the tear.

Ninetytwo eyes of 92 consecutive patients with GRTs underwent vitrectomy and fluid/silicone-oil exchange at Moorfields Eye Hospital between January 1979 and December 1982. Nineteen patients mostly from abroad failed to reattend for long-term follow-up and could not therefore be documented. We report the findings at six months after surgery in the 73 eyes for which information was available.

There were 57 males and 16 females, their ages ranging from 4 to 71 years. Twentysix patients presented more than two weeks after the onset of symptoms, and in 63 out of 73 eyes the macular retina was detached at the time of surgery. The GRT was $180^{\circ}$ or greater in extent in 40 cases and less than $180^{\circ}$ in 33. In six cases a previous attempt to close the GRT by other techniques had been undertaken. In six cases there was a family history of retinal detachment, and in seven there was a history of retinal detachment in the fellow eye. In three of these fellow eyes the retinal detachment was associated with multiple $U$ tears and in one with a GRT, while in two with dense cataracts and one with anophthalmos the pathogenesis of the retinal detachments could not be determined. Twentysix of the 73 patients were highly myopic, four showed signs of the Stickler syndrome, and two had Marfan's syndrome. In 16 there was a history of trauma. Twelve eyes were aphakic, seven 


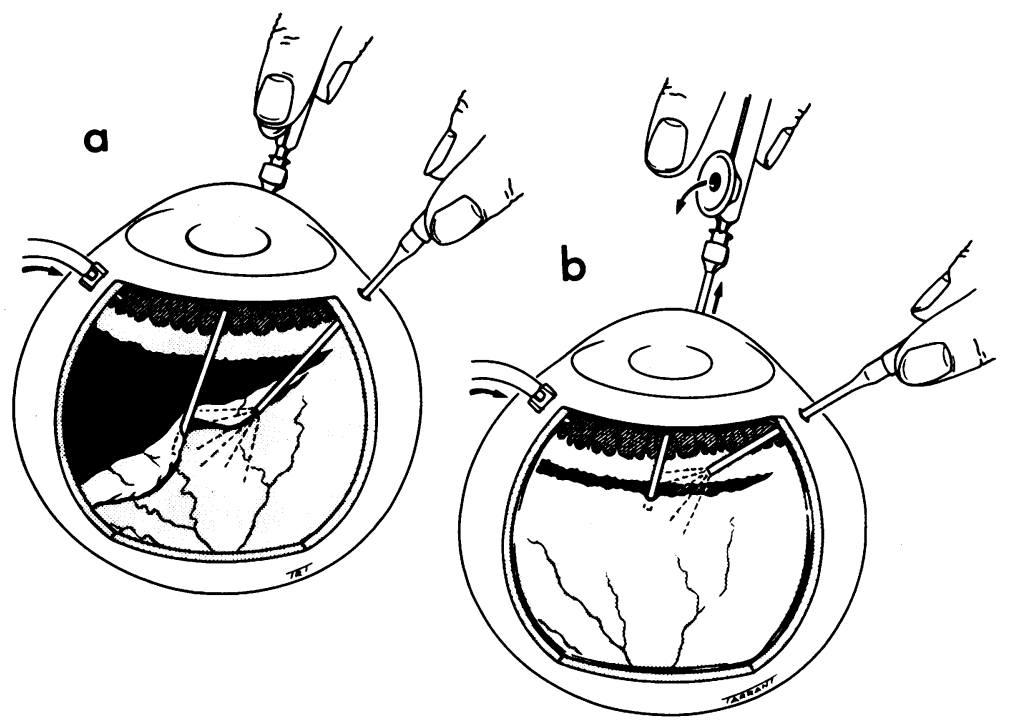

Fig. 1a Manipulation of the posterior flap of the giant retinal tear by means of the flute needle and light pipe. Note that the venting orifice of the flute needle is kept closed during this manoeuvre to prevent incarceration of retina in the needle aperture. $\mathrm{b}$ Drainage of subretinal fluid from behind the posterior flap of the giant retinal tear during the latter stages of fluid/silicone-oil exchange.

as a result of trauma and five following elective cataract extraction. One eye was buphthalmic.

\section{SURGICAL METHOD}

Vitrectomy and fluid/silicone-oil exchange

Bimanual closed intraocular microsurgery was performed in all cases with common gauge instrumentation, infusion contact lens, and the Zeiss OpMi VI microscope with X-Y coupling. A complete vitrectomy was carried out, with care being taken to remove all gel obstructing free mobilisation of the posterior flap of the GRT. In 16 cases lensectomy was performed either to increase the field of view or to preempt development of silicone-oil-induced cataract.

The posterior flap of the GRT was unfolded by direct intraocular manipulation (with the light pipe and flute needle or vitrectomy instrument) before injecting silicone oil of 1000 centistokes viscosity into the eye via the infusion line and terminal which had initially been used for the infusion of physiological solution (Fig. 1a). Injection was facilitated by a compressed air driven syringe operated by a footswitch (SOP unit: G. Vyfvinkel, Oogzekanhuis, Rotterdam, Holland).

Simultaneous evacuation of intraocular fluid was effected by a modified Charles flute needle as the injection of silicone oil proceeded. The posterior flap of the GRT was kept under constant observation and manipulated as and when necessary. Subretinal fluid which did not transfer to the preretinal space during the course of exchange was tapped from under the retina through the GRT by means of the flute needle (Fig. 1b). Occasionally a deliberate retinotomy was created to allow internal drainage of subretinal fluid trapped posteriorly after the GRT had closed.

\section{Cryotherapy and buckling}

Cryopexy through full thickness sclera was applied to the posterior edge of the GRT and to the untorn retinal periphery after the tear had been closed and

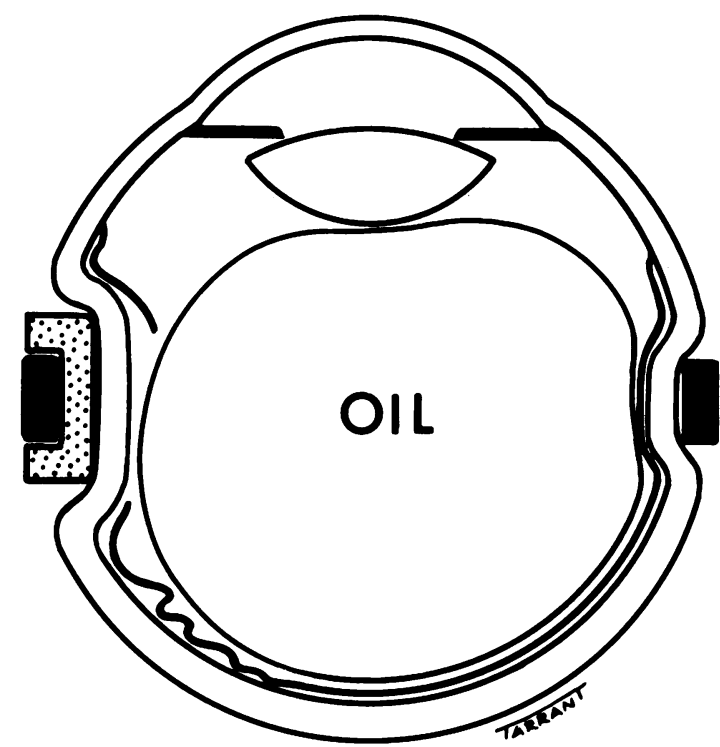

Fig. 2 Diagram illustrating the tendency for the posterior flap of a giant retinal tear to slip backwards off a deep circumferential buckle. 
the retina reattached. Care was taken to ensure freezing of both retina and retinal pigment epithelium, especially around the limits of the GRT and of satellite breaks if present. In the earlier cases in this series a silicone rubber band was used to encircle the globe and a solid silicone rubber gutter placed under the band in the bed of the tear. Because of the tendency to fishmouthing and slippage of the posterior flap after circumferential buckling (Fig. 2) the use of a band was usually avoided in later cases, and either no buckle was used or a no. 287 tyre was placed between 4 and 8 o'clock in the lower half of the globe to support the inferior retina and lower end of the GRT only.

The sclerotomies were closed with $8 / 0$ Ethilon sutures and subconjunctival injections of Cephaloridine $125 \mathrm{mg}$ and Betnesol (betamethasone) $4 \mathrm{mg}$ given after closure of the conjunctiva. $360^{\circ}$ cryopexy through full thickness sclera was applied to the fellow eye as a prophylactic measure in appropriate cases.

\section{POSTOPERATIVE MANAGEMENT}

Patients were nursed in the face down position as soon as possible after surgery and thereafter for 3 or 4 days either in or out of bed. Subsequently they were allowed to mobilise but instructed never to lie in the supine position for extended periods of time.

Hospital admission was usually restricted to less than one week, and follow up examinations were conducted at intervals of one to three weeks for the first few weeks after discharge and at extended intervals thereafter.

\section{REOPERATIONS}

In 9 cases further operative procedures were carried out within one month of the initial surgery because the GRT reopened or new tears developed inferiorly. In five other instances epiretinal membranes were peeled from the macula, and in four cases a drainage procedure was undertaken since raised intraocular pressure could not be controlled satisfactorily with medical treatment. In nine phakic eyes lens extraction was undertaken within the six-month follow-up period, in seven because of cataract and in two because silicone oil entered the anterior chamber and threatened to compromise the corneal endothelium.

In 46 cases in which the retinal break(s) were judged to be securely sealed the silicone oil was removed from the eye by the method previously reported ${ }^{3}$ (Fig. 3), after six to 10 weeks (in 32 in an attempt to pre-empt the development of silicone-oil induced cataract, in eight because of raised intraocular pressure, and in six because of corneal endothelial contact with the oil globule). In four of these 46 eyes silicone oil was subsequently reinjected because of redetachment.

\section{OIL STATUS AT SIX MONTHS}

In 31 eyes silicone oil remained in situ at six months in seven eyes because surgery had failed and in 24 in which the retina remained attached. Of these 24 cases 16 were aphakic with a deep anterior chamber present in front of the oil globule, so that silicone oil removal was not indicated. Of the 8 phakic cases it was felt that the breaks might not be sealed securely in 7 , and one patient refused to undergo further surgery.

\section{Results}

Closure of the GRT with reattachment of the retina at or immediately after surgery was achieved in 71 out of 73 eyes $(97 \%)$. (Similar initial anatomical success, 89 out of 92 cases [ $97 \%$ ], was achieved in the original consecutive series.)

In 11 cases redetachment occurred within one month of surgery owing to development of new breaks or reopening of the original break. In six of these eyes further surgery, namely external buckling and
Fig. 3 Method of removing silicone oil by infusing physiological fluid through a cannula in the pars plana and allowing the silicone oil to escape through a $3 \mathrm{~mm}$ long circumferential incision a in the pars plana in the phakic eye and $\mathrm{b}$ at the limbus in the aphakic eye.
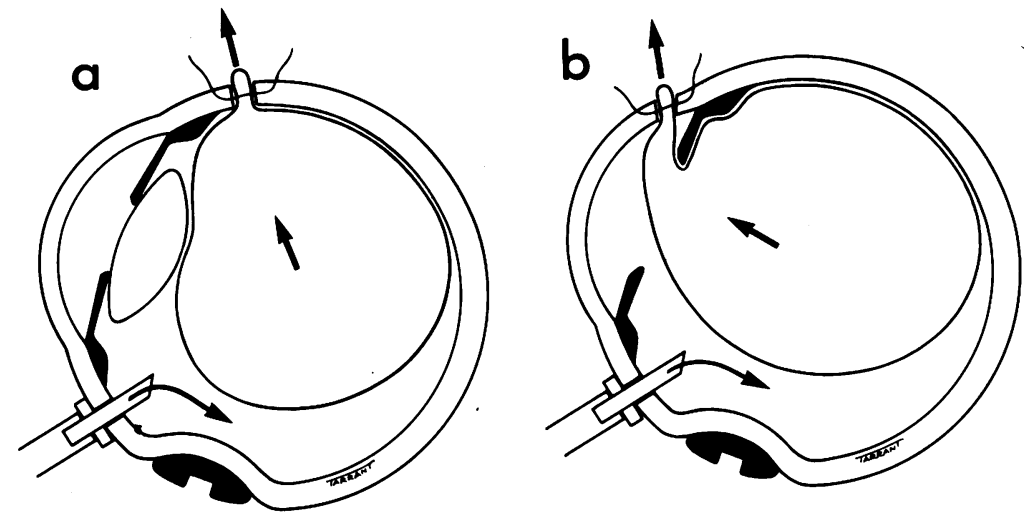


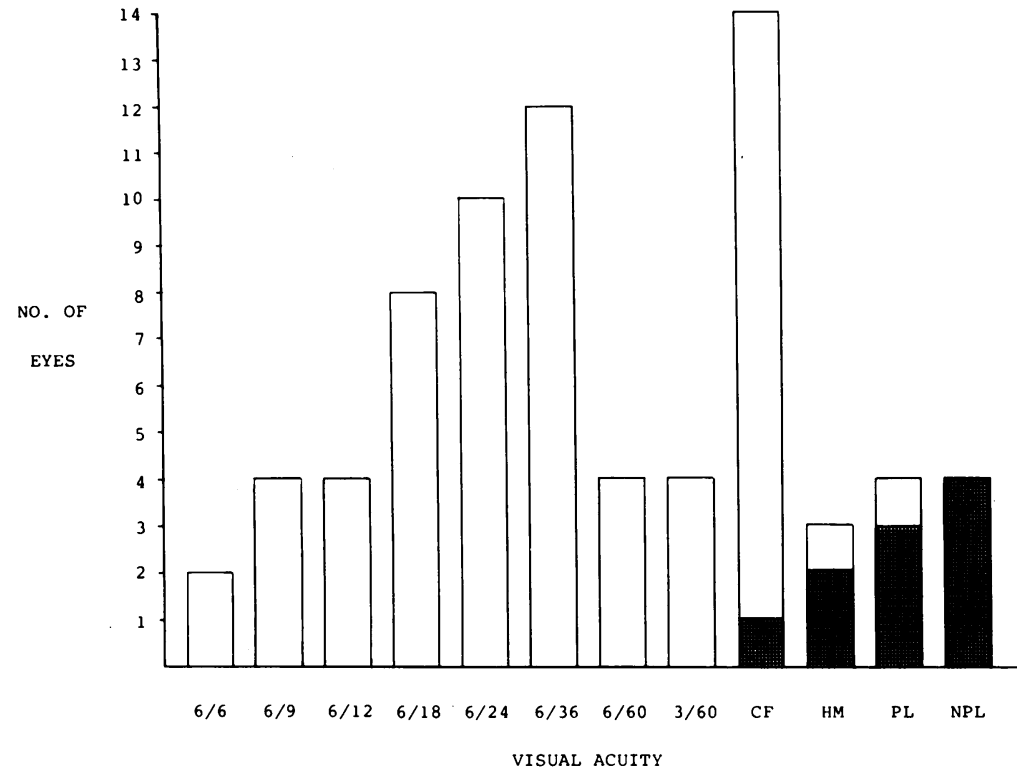

Fig. 4 Results six months after vitrectomy and fluid/silicone-oil exchange in 73 eyes with giant retinal tears. $\square=$ Anatomical success. $\mathbf{D}=$ Anatomical failure. cryopexy, was successful in closing the break. In three it failed, and in two no further surgery was undertaken. Anatomical success prior to removal of silicone oil was therefore achieved in 66 out of 73 eyes $(90 \%)$.

Silicone oil was removed from 46 eyes at between six and 10 weeks after surgery, and in 13 of these eyes $(28 \%)$ the retina subsequently redetached owing to reopening of the GRT (usually at its inferior limit) or to the development of fresh tears. Successful reattachment was achieved in four eyes by refilling with silicone oil and in six by means of sulphurhexafluoride/air mixture. The retina remained detached in 3 eyes, in one because of inoperable massive periretinal proliferation, in one because the eye had been amblyopic prior to surgery and no further intervention was considered justified, and one patient refused further surgery.

In summary, the retina remained attached at six months in 63 eyes $(86 \%)$ while in 10 it was detached $(2$ failures at surgery, five in the early postoperative period, and three after silicone-oil removal). The visual results at six months were as follows: of the 63 eyes with an attached retina $44(70 \%)$ had visual acuities of $6 / 60$ or better (of which $18(29 \%$ ) saw $6 / 18$ or better and $26(41 \%)$ saw $6 / 24$ to $6 / 60)$. In 19 eyes $(30 \%)$ vision was $3 / 60$ or worse. In the 10 anatomical failures visual acuities ranged from counting fingers to no perception of light (Fig. 4).

\section{SIZE OF TEAR}

Successful closure of the GRT and retinal reattachment was recorded at six months in 35 of 40 eyes
$(88 \%)$ with GRTs of $180^{\circ}$ or greater in extent and in 28 out of 33 eyes $(85 \%)$ with breaks of less than $180^{\circ}$. In eyes with tears of $180^{\circ}$ or greater the visual acuities at six months were $6 / 60$ or better in 23 out of $40(58 \%)$ and in eyes with tears of less than $180^{\circ}$ in 21 out of 33 (64\%) (Fig. 5).

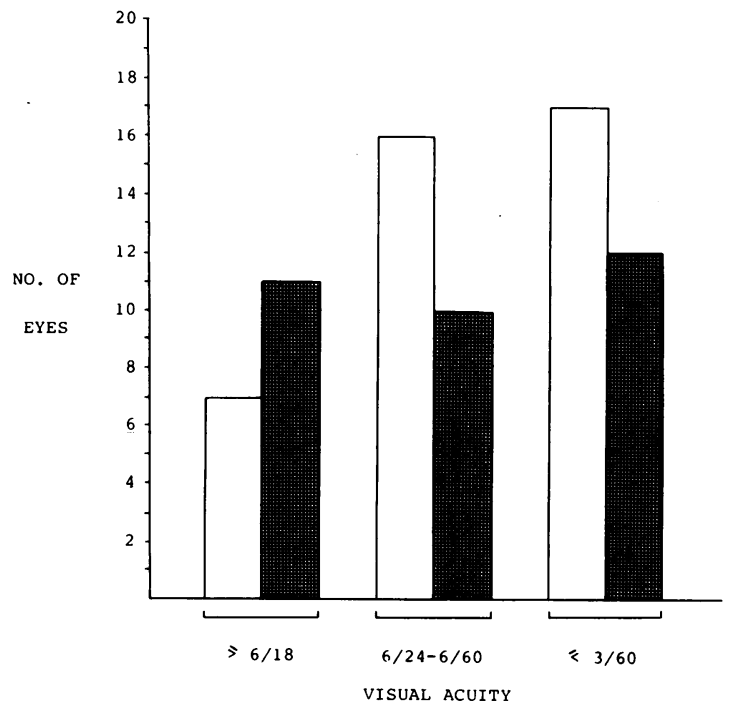

Fig. 5 Results six months after surgery in 40 eyes with giant retinal tears $180^{\circ}$ or greater in extent compared with 33 eyes with giant retinal tears of less than $180^{\circ} . \square=$ Tear $\geqslant 180^{\circ}$. $=$ Tear $<180^{\circ}$ 
Fig. 6 Histogram relating the visual results in 63 anatomically successful cases six months after surgery to the incidence of late complications. $M=$ Maculopathy. $P=$ Pucker. $C=$ Cataract .

K=Keratopathy. ${ }^{*}=$ Amblyopia .

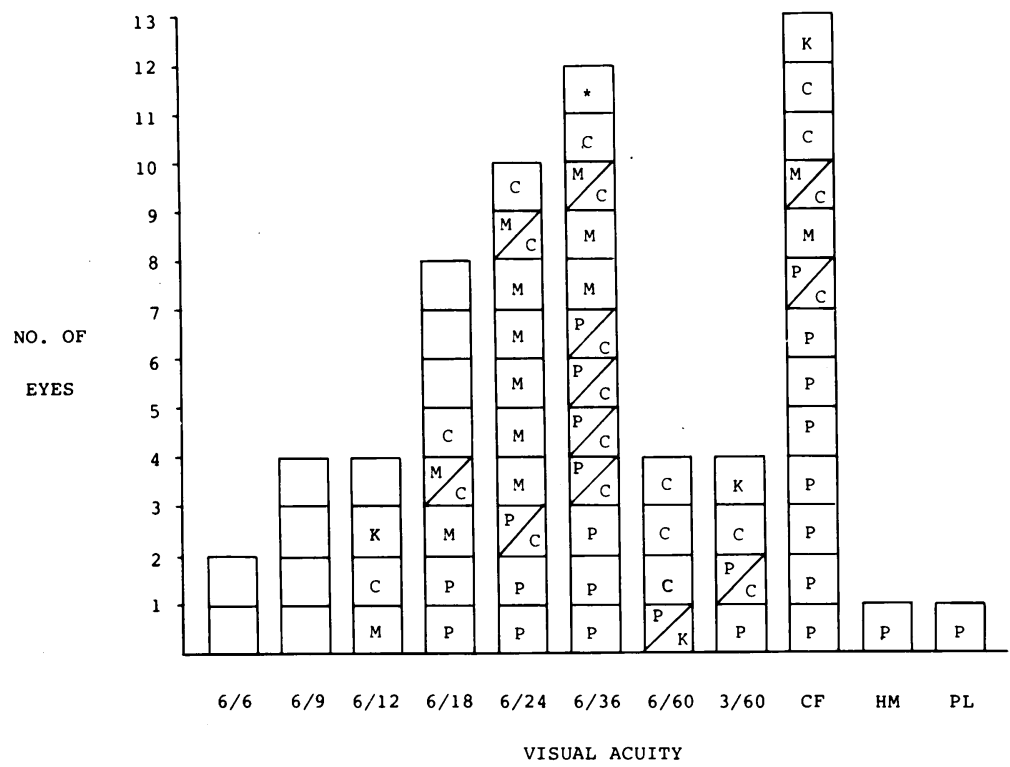

three the endothelial decompensation was associated with previous penetrating trauma and in one with contact of the silicone oil globule with the corneal endothelium. All are designated keratopathy in Fig. 6.

\section{INTRAOCULAR PRESSURE}

In 15 cases the intraocular pressure at six months was found to be outside the accepted upper limit of the normal range or to have been so prior to treatment. Nine of these 15 eyes had suffered blunt trauma and/or complicated cataract extraction prior to developing a GRT. One was a case of Marfan's syndrome with subluxated lens, and five had normal anterior segments prior to undergoing lensectomy at the time of vitreoretinal surgery. In 11 cases the intraocular pressure ranged from 14 to $30 \mathrm{mmHg}$ on medical treatment, while in the four which underwent drainage procedures, three trabeculectomy and one insertion of a Molteno tube, it ranged from 5 to 28 $\mathrm{mmHg}$.

\section{Discussion}

A review of the literature reveals few large series of GRTs with long-term follow-up data. ${ }^{25813-16}$ In some reports there is inadequate information about the final levels of vision, ${ }^{131617}$ while in others spontaneous retinal dialyses appear to have been intermingled with true GRTs. ${ }^{1718}$ This distinction is important, because in dialyses the vitreous gel is attached to the posterior edge of the break, posterior
CORNEAL STATUS

Corneal oedema was present at six months in four of the 63 eyes with successful retinal reattachment. In 
vitreous detachment is seldom present, and massive periretinal proliferation is rare, while in GRTs (where the gel is attached essentially to the anterior flap), the vitreous is usually detached posteriorly and massive periretinal proliferation and/or macular pucker are very common.

The rate of anatomical success is encouragingly high in this series, and it is interesting that, unlike most other workers, ${ }^{13-17}$ we found very little difference in outcome in eyes with tears of less than $180^{\circ}$ compared with those with tears of $180^{\circ}$ or greater (Fig. 5). This is less surprising when one considers that the increased mobility of the posterior flap in very large tears frequently makes their reapposition easier, while the nature of silicone-oil tamponade means that it can be applied throughout the extent of the tear for as long as necessary (whereas a shrinking gas bubble may, though initially adequate, become ineffective within a few days of surgery).

Silicone oil has several properties which make it particularly appropriate for the management of GRTs. Because of its high viscosity ingress into the eye is slow and easily controlled. There is little tendency for oil to leak from the sclerotomies, and exchange of preretinal fluid is unhurried. Its high refractive index allows visualisation of fundus details through the operating microscope throughout the course of the exchange even in the phakic eye, and manipulation of instruments within and behind the silicone-oil globule is thereby facilitated. Furthermore, owing to its drying effect, the clarity of the lens or cornea is assured when silicone oil is in contact with it for short periods.

The low density and hence 'buoyancy' of silicone oil is an advantage, as it facilitates the surgery of GRTs in the supine position, thus obviating the need for rotating operating tables and contortions on the part of the surgeon. Because the oil globule rises towards the front of the eye during injection it expands slowly backwards, meeting the posterior retina only when it is already of a large size and has little tendency to pass behind the retina. Only if the silicone exchange is completed with the posterior flap of the GRT actually retroflexed does the oil globule prevent the tear from closing. It is the combination of all these factors which make silicone oil so well suited to the treatment of GRTs, unlike gases, which have low viscosities and Healon, which exerts no significant surface tension effect.

Massive periretinal proliferation and macular pucker are common complications of GRTs. The development and proliferation of epiretinal membranes on the retinal surface in cases of GRT may reflect massive invasion of the preretinal space by retinal pigment epithelial cells encouraged by the enormous size of the tear and extent of posterior vitreous detachment. While there is no evidence to suggest that silicone oil has any influence on the proliferation of pigment epithelial or other cells on the retinal surface ${ }^{1920}$ it may be influential in other ways. ${ }^{21}$ It is conceivable for instance that the silicone oil, by closing the GRT completely prior to the application of cryopexy, denies circulating cells access to the retinal surface during this phase of the operation, while postoperatively, because it cannot pass across the retina except through a rigid retinal tear it prevents recruitment of subretinal fluid from the preretinal space.

In view of the high rate of anatomical success in this series the visual results are somewhat disappointing. There are two reasons for this; firstly, the high incidence and long duration of macular detachment prior to surgery, and secondly, the development of late complications (Fig. 6). It is worth noting that the visual results at six months in successful cases in which the macular retina was attached prior to surgery were considerably better than those in eyes with preoperative macular detachment. The use of silicone oil has been much criticised, particularly in the USA, because of fears about retinal toxicity ${ }^{22-24}$ and concern over late complications arising as a result of its use. ${ }^{25-29}$ There is now firm evidence to refute the allegations made by Schepens and his group concerning retinal toxicity, ${ }^{30-32}$ but equally the high incidence of long-term complications is not in doubt. ${ }^{33-35}$ Of our successful cases (19 in all) in which visual acuity was $3 / 60$ or less at six months the great majority had macular abnormalities owing to epiretinal membrane contraction or postdetachment atrophy/oedema (Fig. 6). In only three of these 19 eyes was cataract felt to be the main reason for poor acuity, while of the two eyes with corneal decompensation and oedema this was secondary to siliconeoil contact in only one. Furthermore, in no instance did raised intraocular pressure appear to be a major factor in determining the level of acuity at six months.

It is thus evident that at six months after vitrectomy and fluid/silicone-oil exchange poor vision most commonly results from complications of the disease process itself rather than from the use of silicone oil. However, the development of some degree of lens opacity in all but 8 of the successful cases suggests that cataract may become an increasingly important cause of reduced vision in the long term, and the possibility of preventing this complication by removing the silicone oil at an earlier stage than six to 10 weeks is at present being explored.

Further studies of this cohort of 73 eyes will attempt to identify future changes in visual function and to discover if these result from complications of the disease process itself or from the surgical method. Such changes in vision may be for the worse (in the 
event of, say, increasing macular pucker or cataract) or for the better following membrane peeling or cataract extraction. Detailed studies to evaluate the late complications of silicone-oil injection are already being undertaken with particular reference to the development of postoperative cataract and glaucoma.

Our thanks are due to Miss Heather Lucas for typing the manuscript and preparing Figs. 4, 5, and 6; to Mr T. Tarrant for Figs. 1, 2, and 3; and to the Department of Medical Illustration, Moorfields Eye Hospital, for photographic services. We are indebted to Dr Harvey Lincoff and Dr S. E. Powrie for their helpful advice and encouragement in the preparation of this paper.

\section{References}

1 Federman JL, Shakin JL, Lanning RC. The microsurgical management of giant retinal tears with transscleral retinal sutures. Trans Am Acad Ophthalmol Otolaryngol 1982; 89: 832-9.

2 Frecman HM, Castillejos ME. Current management of giant retinal breaks: results with vitrectomy and total air fluid exchange in 95 cases. Trans Am Ophthalmol Soc 1981; 79: 89-102.

3 Leaver PK, Lean JS. Management of giant retinal tears using vitrectomy and silicone-oil/fluid exchange. A preliminary report. Trans Ophthalmol Soc UK 1981; 101: 189-91.

4 Lean JS, Leaver PK, Cooling RJ, McLeod D. Management of complex retinal detachments by vitrectomy and fluid/silicone exchange. Trans Ophthalmol Soc UK 1982; 102: 203-5.

5 Machemer R, Allen AW. Retinal tears $180^{\circ}$ and greater. Arch Ophthalmol 1976; 94: 1340-6.

6 Fitzgerald CR. The use of healon in a case of rolled-over retina. Retina 1981; 1: 227-31.

7 Usui M, Hamazaki S, Takano S, Matsuo H. A new surgical technique for the treatment of giant tear: transvitreoretinal fixation. Jpn J Ophthalmol 1979; 23: 206-15.

8 Živojnovic R, Mertens DAE, Peperkamp E. Das flussige silikon in der amotiochirurgic (II). Bericht über 280 falle-weiterc Entwicklung der Technik. Klin Monatsbl Augenheilkd 1982; 181: 444-52.

9 Scott J. Giant tear of the retina. Trans Ophthalmol Soc UK 1975; 95: 142-4.

10 Scott J. Equatorial giant tears affected by massive vitreous retraction. Trans Ophthalmol Soc UK 1976; 96: 309-12.

11 Scott J. Use of liquid silicone in vitrectomised eyes. Dev Ophthalmol 1981; 2: 185-90.

12 Cleary PE, Leaver PK. Macular abnormalities in the reattached retina. Br J Ophthalmol 1978; 62: 595-603.

13 Kanski JJ. Giant retinal tears. Am J Ophthalmol 1975; 79: 846-52.

14 Norton EWD. Aaberg T, Fung W, Curtin V. Giant retinal tears. I. Clinical management with intravitreal air. Am J Ophthalmol 1969; 68: 1011-21.
15 Schepens CL, Freeman HM. Current management of giant retinal breaks. Trans Am Acad Ophthalmol Otolaryngol 1967; 71: 474-87.

16 Wessing A, Spitznas M, Palomar A. The surgical treatment of retinal detachment due to equatorial giant tears. Mod Probl Ophthalmol 1975; 15: 328-31.

17 Hunyor ABL. Giant retinal tears. Trans Ophthalmol Soc NZ 1976; 28 : 107-10.

18 Lincoff $\mathrm{H}$, Kreissig I, LaFranco F. Mechanisms of failure in the repair of large retinal tears. Am J Ophthalmol 1977; 84: 501-7.

19 Fastenburg DM, Diddie KR, Delmage JM, Dorey K. Intraocular injection of silicone-oil for experimental proliferative vitreoretinopathy. Am J Ophthalmol 1983; 95: 663-7.

20 Lean JS, van der Zee WAM, Ryan SJ. An experimental model of proliferative vitreoretinopathy (PVR) in the vitrectomised cyc: the effect of silicone oil. BrJ Ophthalmol (in press).

21 Gonvers M. (1983). Silicone-oil and proliferative vitreoretinopathy: report presented at 4th Vitrectomy Symposium, Vail, Colorado.

22 Lee P, Donovan RH, Mukai N, Schepens CL, Freeman HM. Intravitreous injection of silicone-an experimental study. $\mathrm{I}$. Clinical picture and histology of the eye. Ann Ophthalmol 1969; 1: $15-25$

23 Mukai N, Lee $P$, Schepens $C L$. Intravitreous injection of silicone -an experimental study. II. Histochemistry and electronmicroscopy. Ann Ophthalmol 1972; 4: 273-87.

24 Mukai N, Lee P, Oguri M, Schepens CL. A long term evaluation of silicone retinopathy in monkeys. Can J Ophthalmol 1975; 10: 391-402.

25 Blodi FC. Injection and impregnation of liquid silicone in ocular tissues. Am J Ophthalmol 1971; 71: 1044-51.

26 Cockerham WD, Schepens CL, Freeman HM. Silicone injection in retinal detachment. Arch Ophthalmol 1970; 83: 704-12.

27 Manschot WA. Intravitreal silicone injection. Adv Ophthalmol 1978; 36: 197-207.

28 Sugar HS, Okamura DD. Ocular findings six years after intravitreal silicone injection. Arch Ophthalmol 1976; 94: 612-5.

29 Watzke RC. Silicone retinopoiesis for retinal detachment. A pathological report. Surv Ophthalmol 1967; 12: 333-7.

30 Constable I, Mohamed S, Tan PL. Super viscous silicone liquid in retinal surgery. Aust J Ophthalmol 1982; 10: 5-11.

31 Meredith TA, Lindsay D, Edelhauser HF, Goldman AI. Elcctroretinographic studies following vitrectomy and intraocular silicone-oil injection. Am J Ophthalmol (in press).

32 Ober RR, Blanks JC, Ogden TE, Pickford M, Minckler DS, Ryan SJ. Experimental retinal tolerance to liquid siliconc. Retina 1983; 3: 77-84.

33 Grey RHB, Leaver PK. Results of silicone-oil injection in massive preretinal retraction. Trans Ophthalmol Soc UK 1977; 97: 238 -41 .

34 Leaver PK, Grey RHB, Garner A. Silicone-oil injection in the treatment of massive preretinal retraction. II. Late complications in 93 eyes. Br J Ophthalmol 1979; 63: 361-7.

35 Okun E. Intravitreal surgery utilizing liquid silicone: a long term follow up. Trans Pac Coast Otoophthalmol Soc 1968; 49: 141-59. 